\title{
informa
}

healthcare

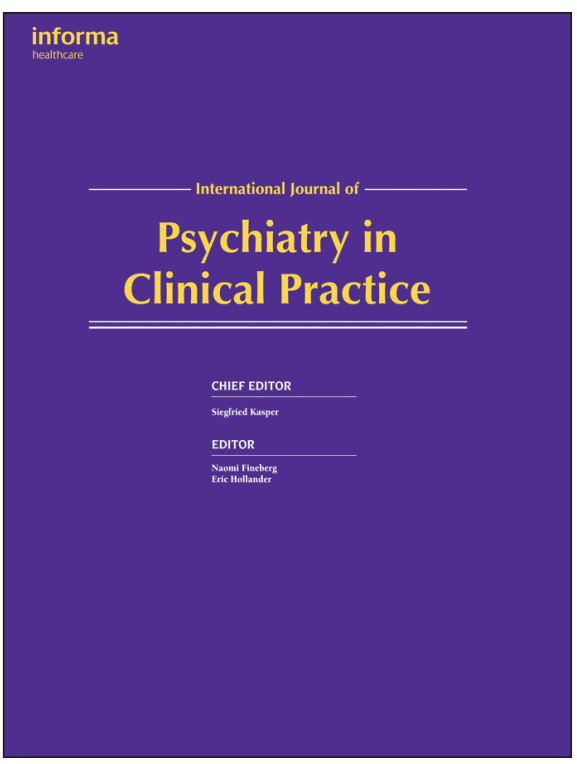

Just Accepted by International Journal of Psychiatry in Clinical Practice

\section{ANTIDEPRESSANT DRUGS AND TEENAGE SUICIDE IN HUNGARY: TIME TREND AND SEASONALITY ANALYSIS}

Otuyelu Ekundayo, Anett Foldvari, Edit Szabo, Valeria Sipos, Peter Edafiogho, Maria Szucs, Peter Dome, Zoltan Rihmer, Janos Sandor

DOI: $10.3109 / 13651501.2015 .1061017$

\section{ABSTRACT}

Objective: The aim of the present study was to analyse the relationship between increasing utilization of antidepressants, lithium and suicide rate of persons less than 20 years of age in Hungary, with particular regard to seasonal patterns.

Methods: Time trend analysis was carried out to determine the correlation between antidepressant and lithium prescription patterns in Hungarian persons under age of 20 as well as seasonal variations within the study period from January 1998 to December 2006.

Results: There was a significant correlation $(p=0.03)$ between the eight-fold increase in antidepressant+lithium prescriptions and decreasing suicides in young Hungarian people under 20 years of age within the study period. Lithium, SSRIs and the group of "other antidepressant drugs" rather than nonselective monoamine reuptake-inhibitors and monoamine oxidase-A inhibitors were responsible for this association. No significant association could be drawn from seasonal variation with boys $(P=0.964)$, girls $(P=0.140)$ or both genders $(\mathrm{P}=0.997)$.

Limitation: Ecological study design

Conclusion: Our findings are in good agreement with large-scale ecological studies showing that the beneficial effect of more widely used antidepressants at a given point could be appear on the level of suicide rate of the general population even among patients under the age of 20 . 


\section{ANTIDEPRESSANT DRUGS AND TEENAGE SUICIDE IN HUNGARY: TIME TREND AND SEASONALITY ANALYSIS}

Otuyelu Ekundayo ${ }^{1}$, Anett Foldvari ${ }^{1}$, Edit Szabo ${ }^{1}$, Valeria Sipos ${ }^{1}$, Peter Edafiogho ${ }^{1}$, Maria Szucs $^{2}$, Peter Dome ${ }^{3,4}$, Zoltan Rihmer ${ }^{3,4}$, Janos Sandor ${ }^{1}$

${ }^{1}$ Department of Epidemiology and Biostatistics, School of Public Health, University of Debrecen, Medical and Health Science Center, Debrecen, Hungary, ${ }^{2}$ Department of Epidemiology, Regional Institute of State Public Health Service, Pecs, Hungary, ${ }^{3}$ Department of Clinical and Theoretical Mental Health, Kutvolgyi Clinical Center, Budapest, Hungary, ${ }^{4}$ Laboratory for Suicide Research and Prevention, National Institute of Psychiatry and Addictions, Budapest, Hungary.

Corresponding Author: Janos Sandor, MD, PhD, E mail: sandor.janos@sph.unideb.hu, Phone No: +36304494973, Department of Epidemiology and Biostatistics, School of Public Health, University of Debrecen Medical and Health Science Center, 26 Kassai Ut. Debrecen, 4028. Hungary.

\section{ABSTRACT}

Objective: The aim of the present study was to analyse the relationship between increasing utilization of antidepressants, lithium and suicide rate of persons less than 20 years of age in Hungary, with particular regard to seasonal patterns.

Methods: Time trend analysis was carried out to determine the correlation between antidepressant and lithium prescription patterns in Hungarian persons under age of 20 as well as seasonal variations within the study period from January 1998 to December 2006.

Results: There was a significant correlation $(p=0.03)$ between the eightfold increase in antidepressant+lithium prescriptions and decreasing suicides in young Hungarian people under 20 years of age within the study period. Lithium, SSRIs and the group of "other antidepressant drugs" rather than nonselective monoamine reuptake-inhibitors and monoamine oxidase-A inhibitors were responsible for this association. No significant association could be drawn from seasonal variation with boys $(P=0.964)$, girls $(P=0.140)$ or both genders $(\mathrm{P}=0.997)$.

Limitation: Ecological study design

Conclusion: Our findings are in good agreement with large-scale ecological studies showing that the beneficial effect of more widely used antidepressants at a given point could be appear on the level of suicide rate of the general population even among patients under the age of 20 .

Keywords: Antidepressant agents, Lithium, Suicide, Seasonality, Children and adolescents, Food and Drug Administration (FDA) 


\section{INTRODUCTION}

In spite of the fact that suicidal behaviour is very complex, multicausal human behaviour, with several psychiatric, psycho-social, demographic and cultural components up to $90 \%$ of all suicide related deaths occur in patients with current major psychiatric disorders out of them untreated major depression is the most common contributory factor (Bertolote and Fleischmann 2002; Rihmer 2007; Hawton and van Heeringen 2009). However, clinical studies show that appropriate acute and long-term treatment of major depression (with antidepressants and/or with lithium) and bipolar disorders (with mood stabilizers, antidepressants and/or antipsychotics) markedly reduces the risk of further suicidal behaviour even in this high-risk patient population (Guzzetta et al. 2007; Rihmer and Gonda 2013).

Given that suicidality is a well-known symptom and outcome of untreated or inadequaately treated depressive illness, the United States Food and Drug Administration Black Box warning" (2004) of emergent suicidality in children and adolescents (extended to young adults in 2006) based on the antidepressant arm of placebo-controlled randomized trials has created understandable concern in clinical practice (FDA 2007; Gibbons et al. 2007). In fact, the meta-analysis of Phase II/III randomized controlled clinical trials on antidepressant monotherapy in unipolar major depression (from which studies the most severe and acutely suicidal patients are excluded, but subthreshold bipolar depressives are included) show a nonsignificant increase of suicidal behaviour (but not completed suicides) in patients taking antidepressants compared to those who are taking placebo (Mann et al. 2006; FDA, 2007). However, the marked antisuicidal effect of antidepressants highly overshadows this rare complication and recent findings show that this relatively small increase in suicidality relates to depression-worsening potential of antidepressant monotherapy (unprotected by mood stabilizers or atypical antipsychotics) in subthreshold bipolar depressives (in clinical trials on unipolar depression) and in unrecognized threshold and subthreshold bipolar depressives (in real life situation) (Akiskal and Benazzi 2005; Rihmer and Gonda 2011; 2013). Although the

Black Box Warning was not officially introduced in Hungary, its main message (i.e. the possible relationship between antidepressant treatment and suicidality), the explanation of this relationship (discussed in the previous sentence) and the possible strategies for minimizing the risk of this rare iatrogeny has been continuously discussed in several 
scientific review papers, book chapters and CME lectures after 2004 in Hungary (Rihmer, 2005, Rihmer et al, 2007).

As the consequence of the FDA Black Box Warning, the recently decreased use of antidepressants in children and adolescents seen in the USA, The Netherlands (Gibbons et al. 2007) and Canada (Katz et al. 2008) has been accompained by a concurrent increase in suicide rates in that age-groups while in middle-aged and old persons, where the utilization of antidepressants increased continuously the suicide rates decreased (Gibbons et al. 2007; Katz et al. 2008). The recent paper by Isacsson and Ahlner (2014) analysed individual date of all 845 suicides in the 10-19 year age group in Sweden during 1992-2003 and 2004-2010. The findings provided further support that the Warning, contrary to its intention, resulted in increasing number of young depressives who did not receive antidepressants and the suicide mortality in this age group increased by 60 percent for five consecutive years. The individual analysis showed that this increase occured among young persons without antidepressant treatment. However, analysing the prescription data of 1.1 million adolescents and 6.4 million adults in the United States between 2000 and 2010, Lu et al. (2014) reported a 31\% decrease in antidepressant prescription among adolescents after 2004, which was accompained by an increase of suicide attempts rather than completed suicides.

In the last 30 years, the suicide rate of Hungary steadily decreased by more than 50 percent while the prescription of antidepressants increased by ten-fold (Rihmer et al. 2013). Analyzing the prescription of antidepressants and suicide mortality in the whole population of Hungary between 1998 and 2006 there was a significant correlation between the steadily increasing antidepressant prescription (113\%) and continuous decline in total national suicide rate $(23 \%)$ as well as both in females and males $(21 \%$ and $23 \%$, respectively). Increasing antidepressant utilization was associated with significantly decreased seasonality of suicides only among males (Sebestyén et al. 2010). The steep increase in prescription of antidepressants and the still high prevalence of suicides in Hungary (Döme et al. 2011; Rihmer et al. 2013) provided an opportunity by which the nature of the association between antidepressant drug use and suicide could be evaluated separately among persons less than 20 years old in the same data base used in our previous study (Sebestyén et al. 2010). Based on the evidence that pharmacotherapy of depression is highly beneficial for suicide mortality (Rihmer and Gonda 2013) we worked with the hypothesis that antidepressants by treating 
depression, the major risk factor for suicide, would result in a reduction in suicide mortality in young persons under age of 20 too. Because seasonality of suicides is mainly the consequence of the seasonal incidence of depression-related suicides, suggesting that decreasing seasonality of suicides might be a marker of lowering rate of depressive suicides in the population (Rihmer et al. 1998, Mergl et al. 2010; Sebestyén et al. 2010), we have postulated that this reduction would be most visible in the months when suicide peaks resulting in a decreasing seasonal variation of suicide death rates. The antisuicidal effect of lithium is well-known (Guzzetta et al. 2007; Rihmer and Gonda 2013) but according to our best knowledge there is no study yet on the possible association between the amount of lithium prescribed at the level of population and suicide rates in Hungary.

Shortly, our primary aim was to check the adequacy of the concern of the FDA about the safety of antidepressants among children and adolescents with investigating the association between the amount of antidepressants (and lithium) prescribed and suicide rate in people under 20 years of age in a country where Black Box Warning for antidepressants (FDA, 2007) has not been applied.

MATERIALS AND METHODS

Suicide Data

Mortality data was sourced from the Hungarian Central Statistical Office describing deaths due to suicides in Hungary from January 11998 to December 31 2006. Suicide rates were classified based on age (children and adolescents less than 20 years categorized into 5 year groups) as well as gender, each classification having its calculations for monthly and annual number of suicide related deaths. The suicide rates obtained were standardized for age and gender using the Hungarian population at the beginning of 2008 as standard. The indicator used was standardized death rates (SDR) calculated as the number of suicides/100,000 inhabitants/year. 
On the other hand, the number of suicide deaths and the average daily number of deaths were determined for each investigated bimonthly period. The average and the standard deviation of these average daily case numbers were estimated for each year of our study as well. The variation coefficient for each year was calculated as the standard deviation / mean of daily number of suicide deaths for all of studied years. This indicator was used in describing the seasonality.

\section{Antidepressant and lithium prescription data}

Data on antidepressant and lithium prescription was obtained from the Hungarian National Health Insurance Fund (NHIF). This also covered the whole country as the suicide data collected and spanned 9 years (January 1 1998 to December 31 2006). Health insurance being mandatory for every citizen living in Hungary suggests that we can safely assume that antidepressant prescription data from the NHIF (which has the personal identification and prescriptions of all insured persons) gives a true representation of the national drug prescription.

The psychotropic drugs (with ATC codes) for which data was collected included the following groups: lithium (N05AN01), antidepressants: nonselective monoamine reuptake inhibitors (N06AA), selective serotonin reuptake inhibitors (SSRIs, N06AB), monoamine oxidase-A inhibitors (RIMA, N06AG), all other drugs used in the treatment of depression (N06AX). Our database contained the amount and ATC codes of antidepressant drugs prescribed for teenagers less than 20 years old by gender, and by year studied, respectively. The drug prescription was 
summarized for the above mentioned ATC categories and for all antidepressants and lithium applying WHO defined daily doses. The indicator describing lithium and antidepressant drug use was the Daily Defined Dose (DDD) for 1,000 inhabitants per day in each year studied.

\section{Statistical Analyses}

Regression coefficients from Autoregressive Integrated Moving Average (ARIMA) method were used to describe association between time trend of standardized suicide death rates and prescribed doses of antidepressants. ARIMA was also applied to investigate the relationship between the trend of antidepressant drug prescription and the seasonality index in suicide rates (Box et al., 1994). All the investigated variables have been checked by Kolmogorov-Smirnov test for normality before ARIMA application. Analyses were carried out using SPSS 17.0 software. For more detailed description of data collection and statistical analysis see also Sebestyén et al., 2010.

\section{RESULTS}

There were 479 registered suicide deaths (375 boys and 104 girls) in the studied population between 1998 and 2006. The descriptive data are outlined <in Table 1, which highlights continuously increasing amounts of prescription of lithium and individual antidepressant groups. Besides nonselective monoamine reuptake inhibitors, all other groups of lithium and antidepressants had remarkable increase in prescription rates. The combined increase in antidepressant + lithium consumption between 1998 and 2006 
was approximately eightfold while suicide rate among persons under 20 declined by 11 percent.

There was a general inverse association between time-trends of antidepressants + lithium usage and suicide by ARIMA $(b=-0.132 ; p=$ 0.030). Significant association was observed between prescription of lithium $(b=-18.223 ; p=0.032)$, SSRIs $(b=-0.164 ; p=0.026)$, other antidepressants $(b=-0.873 ; p=0.035)$ and teenage suicide rate, suggesting that they might play role in the reduction of suicide related deaths. Nonselective monoamine reuptake inhibitors' as well as RIMAs' influence was not significant in this analysis. (Table 2).

Figure 1 presents the seasonal variations of suicide among teenagers less than 20 year old in Hungary. The boys have a higher occurrence of suicides than the girls (approximately 3 times the value for girls), with suicides tending to peak in the summer months. The seasonality index was calculated as the within year variation coefficient for teenage boys, girls and also as a total estimate for both genders. There was very little change in seasonality for either gender from 1998 till 2006, the final index been almost the same as the start of index. This implies that the standard deviation within each year (corresponding to the fluctuation between peak and low seasons did not change much within our study period). Antidepressant consumption on the other hand as stated earlier showed remarkable increase throughout the period of the study (Table 3).

\section{DISCUSSION}

Since the "Black Box" warning was not considered in Hungary the use of antidepressants continued to increase, but this was not followed by an increase in youth suicide that could have validated the Black Box warning. Our descriptive results demonstrate the moderate 
reducing trend of suicides and the remarkable increase in antidepressant drug prescription in Hungary amongst persons under age of 20, which trend is similar to our previously published finding on the whole population of Hungary during the same time-period (Sebestyén et al. 2010). This inverse association has proved to be significant, suggesting that antidepressant drugs treatment was a contributing factor to the reduction in suicide rates among young patients in Hungary. Lithium, SSRIs and the group of other antidepressant drugs rather than nonselective monoamine reuptake-inhibitors and RIMA antidepressants were responsible for this association. The anti-suicidal effect of lithium - even in unipolar major depression - is well known (Guzzetta et al. 2007, Rihmer and Gonda 2013). It should be noted that in Hungary lithium is frequently used in combination with other antidepressants, but in our present study we could not identified the subpopulation of young patients who receive this combination. However, it can be assumed that the increased coverage of and treatment of depression reduced the complications of depression, foremost of which the most serious and most visible is suicide. Although antidepressants are less frequently effective in children and adolescents than in older persons (Walsh et al. 2002; Bridge et al. 2007), if appropriately used, they treat depression successfully and consequently reduce the risk of suicidal behaviour. The significant role of antidepressants and lithium in reducing suicide mortality of persons under age of 20 is very likely, because several psycho-social and medical risk factors of suicide (like unemployment, divorce/separation, long-lasting alcohol consumption and severe/multiple somatic disorders) (Rihmer 2007; Hawton and van Heeringen 2009) rarely occur in this age group (as a whole). Accordingly, interventions aiming suicide risk reduction among teenagers should focus on other factors such as depression. Our present findings are in good agreement with large-scale ecological studies showing that the beneficial effect of more widely used antidepressants at a given point could be appear on the level of general population (Ludwig et al. 2009; Gusmao et al.2013). Our results also provide indirect support of the studies of Gibbons et al. (2007), Katz et al. (2008) and Isacsson and Ahlner (2014) reporting that the decreased use of antidepressants in children and adolescents after the FDA Black Box Warning has been accompained by a concurrent increase in suicide rates in that age-groups while in middleaged and old persons, where the utilization of antidepressants increased continuously the suicide rates decreased. 
Considering the previously published findings on increased antidepressant utilization and decreasing seasonality of suicidal behaviour (Rihmer et al. 1998; Mergl et al. 2010; Sebestyén et al. 2010) we would have expected that an 8-fold increase in antidepressant drug and lithium prescription should be associated with a corresponding decrease in seasonality index if antidepressant drug use is significantly associated with suicide, but our study showed no such correlation since the seasonality index remained almost unchanged. Increasing antidepressant drug consumption among teenage and young adult Hungarian boys and girls - maybe due to small numbers - seems to have no association with decreasing seasonal variations of suicide related deaths.

Our study has some limitations. Firstly, this is an ecological study, thus it cannot infer causality at an individual level (Robinson 1950). Secondly, we were not able to check whether all the prescribed psychotropic agents were taken by the patients. Thirdly, the rate of patients receiving any antidepressant plus lithium is unknown. The fourth possible limitation of our study is due to that antidepressants are also prescribed for some other disorders (e.g. different kinds of anxiety disorders) than major depression; accordingly it is probable that a small part of antidepressant utilization was occurred among subjects with other diagnosis than depression. However, this bias is negligible if we analyze the long-term trend of change their utilization.

\section{Key points}

- There is a lively debate on the supposed suicide-provoking effects of antidepressants among childen and adolescents.

- Some authors suggested that the within-year seasonal distribution of suicide cases is mainly the consequence of the seasonal incidence of depression-related suicides, suggesting that decreasing seasonality of suicides might be a marker of lowering rate of depressive suicides in the population.

In our ecological study we aimed to discern the correlation between antidepressant and lithium prescription and suicide rate in the Hungarian population aged under 20 years. We also investigated the supposed effect on antidepressant utilization on seasonality of suicides in the same population.

- We found a significant correlation between the increase in antidepressant+lithium prescriptions and decreasing suicides within the study period (1998-2006). On the other hand, we were not able to demonstrate that increasing antidepressant drug consumption would be associated with decreasing seasonal variations of suicide related deaths. 


\section{ACKNOWLEDGEMENTS}

The writers of this paper would like to acknowledge the kind help of the following people:

1. Ede Frecska; the Head, Department of Psychiatry, University of Debrecen Medical and Health Science Center, for allowing us access to the department and taking us through the clinical practice of Psychiatry with particular enlightenment on the issue of suicide and antidepressant use in Hungary

2. Aniko Egerhazi; Attending Psychiatrist, University of Debrecen Medical and Health Science Center, for taking out time to explain the intricate details in the physiology of depression and its management.

3. Attila Nagy; Lecturer in the Department of Epidemiology, University of Debrecen Medical and Health Science Center for his time and effort in proofreading this paper.

4. Roza Adany; Dean School of Public Health, University of Debrecen Medical and Health Science Center, for her guidance and encouragement throughout the course of this research.

\section{CONFLICTS OF INTEREST}

In the last 5 years Dr. Rihmer has received speaker honoraria from AstraZeneca, Eli Lilly, Krka, Lundbeck, Organon, Pfizer, Richter Gedeon Ltd, Sanofi-Aventis, Schering-Plough, Servier-EGIS, Solvay-Pharma TEVA and Wörwag Pharma. He was a member of scientific advisory boards of AstraZeneca, Eli Lilly and Co., Organon, Richer Gedeon Ltd, SanofiAventis, Shering-Plough and Servier-EGIS and TEVA. Other authors declare no conflict of interest. 


\section{REFERENCES}

1. Akiskal HS, Benazzi F. 2005. Psychopathologic correlates of suicidal ideation in major depressive outpatients: is it all due to unrecognized (bipolar) depressive mixed states? Psychopathology 38:273-80.

2. Bertolote JM, Fleischmann A. 2002. Suicide and psychiatric diagnosis: a worldwide perspective. World Psychiatry 1:181-5.

3. Box GEP, Jenkins GM, Reinsel GC. 1994. Time series analysis: Forecasting and Control ( $3^{\text {rd }}$ edition). Upper Saddle River, NJ, Prentice Hall.

4. Bridge JA, Iyengar S, Salary CB, Barbe RP, Birmaher B, Pincus HA et al. 2007. Clinical response and risk for reported suicidal ideation and suicide attempts in pediatric antidepressant treatment: a meta-analysis of randomized controlled trials. JAMA 297:1683-96.

5. Döme P, Kapitány B, Ignits G, Porkoláb L, Ríhmer Z. 2011. Tobacco consumption and antidepressant use are associated with the rate of completed suicide in Hungary: an ecological study. J Psychiatr Res 45:488-94.

6. FDA.

Revisions product labeling. http://www.fda.gov/downloads/Drugs/DrugSafety/InformationbyDru gClass/UCM173233.pdf

7. Gibbons RD, Brown CH, Hur K, Marcus SM, Bhaumik DK, Erkens JA et al. 2007. Early evidence on the effects of regulators' suicidality warnings on SSRI prescriptions and suicide in children and adolescents. Am J Psychiatry 164:135663.

8. Gusmão R, Quintão S, McDaid D, Arensman E, Van Audenhove C, Coffey C et al. 2013. Antidepressant Utilization and Suicide in Europe: An Ecological MultiNational Study. PLoS One 8:e66455.

9. Guzzetta F, Tondo L, Centorrino F, Baldessarini RJ. 2007. Lithium treatment reduces suicide risk in recurrent major depressive disorder. J Clin Psychiatry $68: 380-3$ 
10. Hawton K, van Heeringen K. 2009. Suicide. Lancet $373: 1372-81$

11. Isacsson G, Ahlner J. 2014. Antidepressants and the risk of suicide in young persons--prescription trends and toxicological analyses. Acta Psychiatr Scand 129:296-302.

12. Katz LY, Kozyrskyj AL, Prior HJ, Enns MW, Cox BJ, Sareen J. 2008. Effect of regulatory warnings on antidepressant prescription rates, use of health services and outcomes among children, adolescents and young adults. CMAJ 178:1005-11.

13. Lu CY, Zhang F, Lakoma MD, Madden JM, Rusinak D, Penfold RB et al. 2014. Changes in antidepressant use by young people and suicidal behavior after FDA warnings and media coverage: quasi-experimental study. BMJ 348:g3596.

14. Ludwig J, Marcotte DE, Norberg K. 2009. Antidepressants and suicide. J Health Econ 28:659-76.

15. Mann JJ, Emslie G, Baldessarini RJ, Beardslee W, Fawcett JA, Goodwin FK et al. 2006. ACNP Task Force report on SSRIs and suicidal behavior in youth. Neuropsychopharmacology 31:473-92.

16. Mergl R, Havers I, Althaus D, Rihmer Z, Schmidtke A, Lehfeld $\mathrm{H}$ et al. 2010. Seasonality of suicide attempts: association with gender. Eur Arch Psychiatry Clin Neurosci 260:393-400.

17. Rihmer Z, Rutz W, Pihlgren H, Pestality P. 1998. Decreasing tendency of seasonality in suicide may indicate lowering rate of depressive suicides in the population. Psychiatry Res 81:233-40.

18. Rihmer Z. 2005. (F)okozzák-e az antidepresszívumok a szuicid rizikót ? Psychiatr Hung 20: 380-387. (In Hungarian).

19. Rihmer Z. 2007. Suicide risk in mood disorders. Curr Opin Psychiatry 20: 17-22.

20. Rihmer Z, Gonda X, Szokontor N. 2007. Az antidepresszívumok és az öngyilkosság összefüggése. Gyógyszerészet 15: 139-141. (In Hungarian) 
21. Rihmer Z, Gonda X. 2011. Antidepressant-resistant depression and antidepressantassociated suicidal behaviour: the role of underlying bipolarity. Depress Res Treat 2011:906462.

22. Rihmer Z, Gonda X. 2013. Pharmacological prevention of suicide in patients with major mood disorders. Neurosci Biobehav Rev 37: 2398-403.

23. Rihmer Z, Gonda X, Kapitany B, Dome P. 2013. Suicide in Hungaryepidemiological and clinical perspectives. Ann Gen Psychiatry 12:21.

24. Robinson WS. 1950. Ecological correlations and the behavior of individuals. Am Sociological Rev 15: 351-357.

25. Sebestyen B, Rihmer Z, Balint L, Szokontor N, Gonda X, Gyarmati B et al. 2010. Gender differences in antidepressant use-related seasonality change in suicide mortality in Hungary, 1998-2006. World J Biol Psychiatry 11:579-85.

26. Walsh BT, Seidman SN, Sysko R, Gould M. 2002. Placebo response in studies of major depression: variable, substantial, and growing. JAMA 287:1840-7.

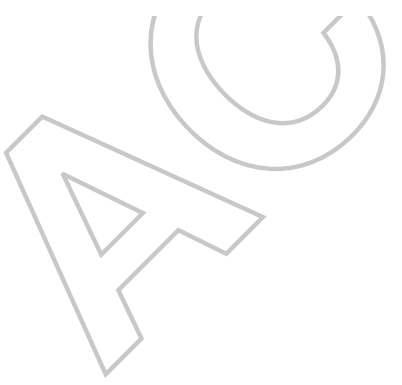




\section{Table Legends}

Table 1. Annual prescription of lithium and antidepressants (DDD/1000 persons/day) with corresponding standardized suicide deaths rates (per 100.000) for young persons ( $<20$ years old) in Hungary between 1998 and 2006.

\begin{tabular}{|c|c|c|c|c|c|c|c|}
\hline Year & Lithium & $\begin{array}{c}\text { Non- } \\
\text { selective } \\
\text { monoami } \\
\text { ne } \\
\text { reuptake } \\
\text { inhibitors }\end{array}$ & $\begin{array}{c}\text { Selective } \\
\text { serotonin } \\
\text { reuptake } \\
\text { inhibitors } \\
\text { (SSRIs) }\end{array}$ & $\begin{array}{c}\text { RIMA } \\
\text { antidep } \\
\text { ressant }\end{array}$ & $\begin{array}{c}\text { Other } \\
\text { anti- } \\
\text { depressant } \\
\text { s }\end{array}$ & $\begin{array}{c}\text { Anti- } \\
\text { depressan } \\
\text { ts + } \\
\text { lithium } \\
\text { together }\end{array}$ & $\begin{array}{c}\text { Suicid } \\
\text { e rate }\end{array}$ \\
\hline 1998 & 0.007 & 0.211 & 0.261 & 0.018 & 0.008 & 0.498 & 2.368 \\
\hline 1999 & 0.008 & 0.245 & 0.512 & 0.040 & 0.022 & 0.818 & 2.966 \\
\hline 2000 & 0.009 & 0.212 & 0.720 & 0.058 & 0.037 & 1.027 & 2.544 \\
\hline 2001 & 0.013 & 0.238 & 1.079 & 0.081 & 0.071 & 1.469 & 2.275 \\
\hline 2002 & 0.018 & 0.263 & 1.438 & 0.117 & 0.168 & 1.986 & 2.735 \\
\hline 2003 & 0.020 & 0.239 & 1.956 & 0.150 & 0.282 & 2.627 & 2.301 \\
\hline 2004 & 0.025 & 0.224 & 2.206 & 0.140 & 0.337 & 2.907 & 2.709 \\
\hline 2005 & 0.026 & 0.252 & 2.770 & 0.160 & 0.372 & 3.553 & 2.121 \\
\hline 2006 & 0.034 & 0.208 & 3.240 & 0.143 & 0.562 & 4.154 & 2.099 \\
\hline
\end{tabular}


Table 2. Association between lithium's and antidepressants' prescriptions

(DDD/1000persons/day) and standardized suicide deaths rates (per 100.000)

among Hungarian children and adolescents ( $<20$ years old) in 1998-2006 by

ARIMA.

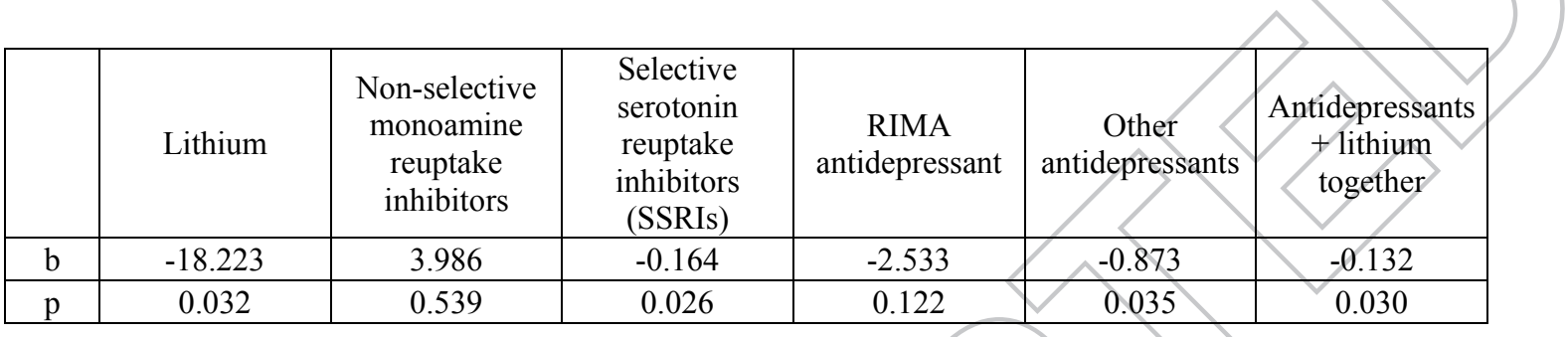

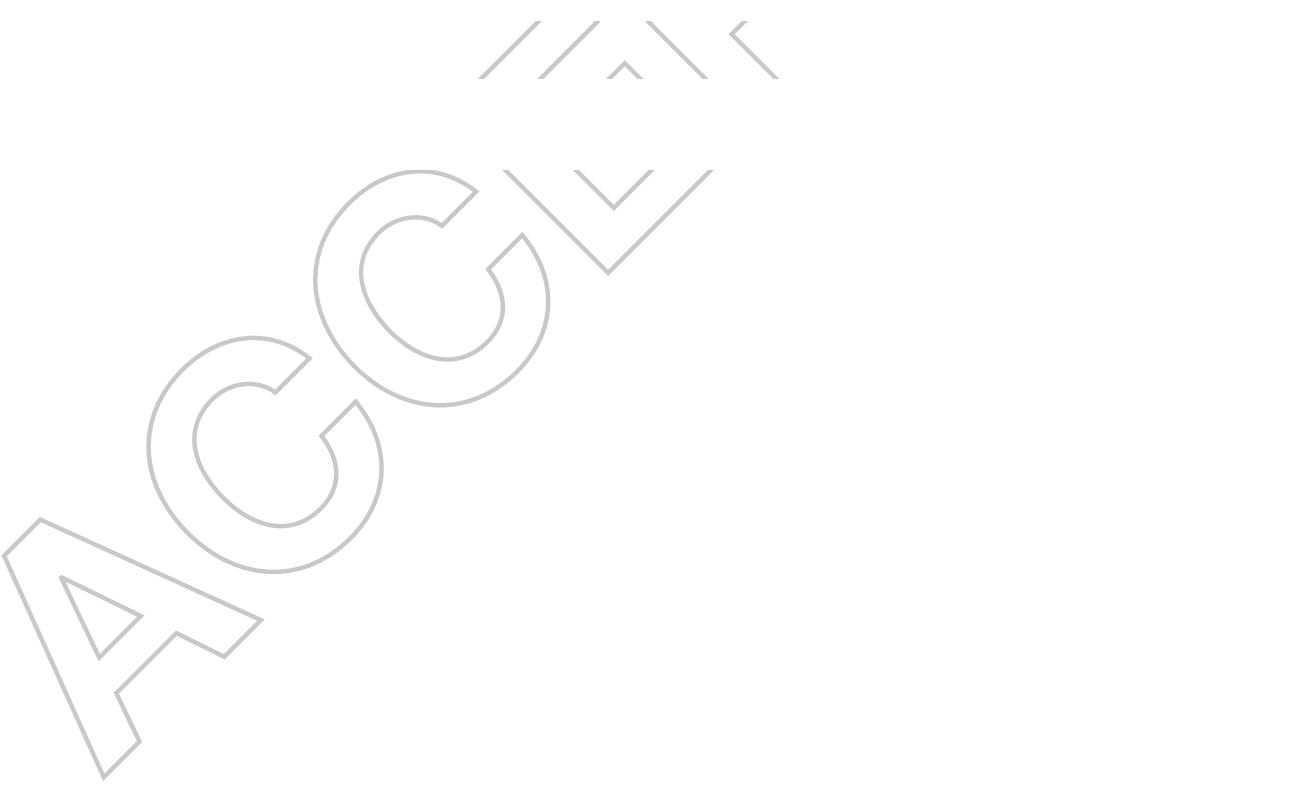


Table 3. Antidepressants' + lithium's prescription (DDD/1000 persons/day) and seasonality index for bimonthly suicide rates among young Hungarian boys and girls ( $<20$ years old) between 1998 and 2006 .

\begin{tabular}{|l|c|c|c|c|c|c|}
\hline $\begin{array}{l}\text { Yea } \\
\text { r }\end{array}$ & $\begin{array}{c}\text { Anti- } \\
\text { depressants } \\
\text { + lithiums' } \\
\text { prescription }\end{array}$ & $\begin{array}{c}\text { Seasonality } \\
\text { index }\end{array}$ & $\begin{array}{c}\text { Bnti- } \\
\text { depressants } \\
+ \text { lithiums' } \\
\text { prescription }\end{array}$ & $\begin{array}{c}\text { Seasonality } \\
\text { index }\end{array}$ & $\begin{array}{c}\text { Total } \\
\text { Anti- } \\
\text { depressants } \\
\text { +lithiums' } \\
\text { prescription }\end{array}$ & $\begin{array}{c}\text { Seasonality } \\
\text { index }\end{array}$ \\
\hline $\begin{array}{l}199 \\
8\end{array}$ & 0.19 & 0.414 & 0.17 & 0.977 & 0.18 & 0.410 \\
\hline $\begin{array}{l}199 \\
9\end{array}$ & 0.30 & 0.450 & 0.30 & 0.865 & 0.30 & 0.434 \\
\hline $\begin{array}{l}200 \\
0\end{array}$ & 0.36 & 0.562 & 0.39 & 0.831 & 0.37 & 0.441 \\
\hline $\begin{array}{l}200 \\
1\end{array}$ & 0.51 & 0.698 & 0.57 & 0.92 & 0.54 & 0.685 \\
\hline $\begin{array}{l}200 \\
2\end{array}$ & 0.65 & 0.521 & 0.80 & 1.085 & 0.72 & 0.451 \\
\hline $\begin{array}{l}200 \\
3\end{array}$ & 0.85 & 0.578 & 1.08 & 0.853 & 0.96 & 0.424 \\
\hline $\begin{array}{l}200 \\
4\end{array}$ & 0.93 & 0.484 & 1.20 & 0.739 & 1.06 & 0.484 \\
\hline $\begin{array}{l}200 \\
5\end{array}$ & 1.11 & 0.517 & 1.50 & 1.431 & 1.30 & 0.537 \\
\hline $\begin{array}{l}200 \\
6\end{array}$ & 1.29 & 0.447 & 1.76 & 1.005 & 1.52 & 0.403 \\
\hline
\end{tabular}

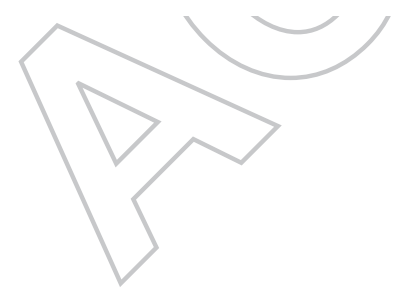


Figure Legend

Figure 1. Within year distribution of 479 suicide deaths (375 boys and 104 girls) among Hungarian adolescents ( $<20$ years old) for the period of 1998 to 2006 by bimonthly number of cases.

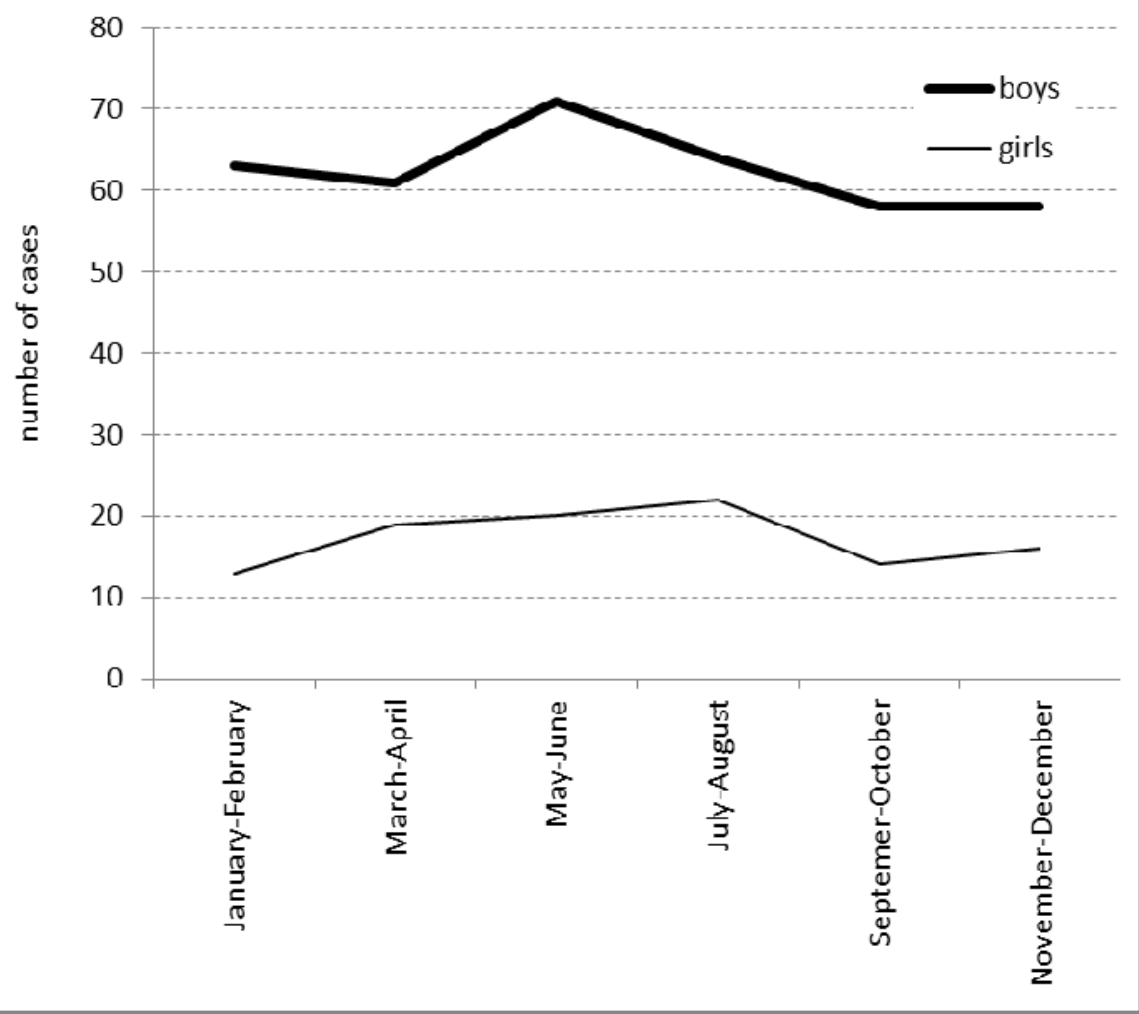

